\title{
Scores and Risk Factors Associated with Burnout Among Professionals of Child and Adolescent Health Care
}

\begin{abstract}
Luciana de Barros Correia Fontes*, Armiliana Soares do Nascimento, Alessandro Leite Cavalcanti, Criseuda Maria Benício Barros, Rosa Maria Mariz de Melo Sales Marmhoud Coury, Darlene Cristina Ramos Eloy Dantas, Virgínia Paula Batista de Brito, Maria da Conceição de Barros Correia, Niedje Siqueira de Lima, Sônia Maria Soares da Silva, Samuel Rodrigo de Andrade Veras and Guilherme Soares Gomes da Silva
\end{abstract}

Department of Clinical and Preventive Dentistry, Federal University of Pernambuco, Brazil

*Corresponding author: Luciana de Barros Correia Fontes, Department of Clinical and Preventive Dentistry, Federal University of Pernambuco, Brazil

\begin{abstract}
Background: In recent dentistry scientific research, it has been observed that worker's mental health has been an object of investigation. Due to several implication both in functional performance and quality of life affiliates by some people with this disorder. This paper reports the prevalence and risk associated with burnout syndrome (BS) in children and adolescent's health care professionals.

Methods: This was a cross-sectional study with descriptive and analytical statistics (based on margin of error 5.0\%). The study area includes the city of Campina Grande, Paraiba State, Northeastern Brazilian. The instruments for data collection were interview with structured questionnaires The Maslach Burnout Inventory-Human Services Survey (MBI-HSS) and a demographic questionnaire were used ( $\mathrm{n}=87)$. For data analysis we used Student's t-test and ANOVA.

Results: The final sample was composed of 63 professionals (72.4\% of the universe). According to the data, $90.5 \%$ of participants were female, mean age 41 years \pm 12.33 . The prevalence of scores related to BS occurred in $49.2 \%$ of investigated; $46.0 \%$ in the initial phase for this disease and 3.2\% with Burnout installed. These patients presented predominantly low level of emotional exhaustion (57.1\%) and moderate levels of depersonalization. All had a high professional achievement. Variables, marital status and family incomes were positively associated with depersonalization.

Conclusion: Approximately half of professionals of health care for children and adolescents reported symptoms related to BS scores, making necessary a more focused approach to the diagnosis and intervention methods to be adopted for the target population discriminated.
\end{abstract}

Keywords: Burnout; Health Personnel; Comprehensive Health Care; Child, Teenager

\section{Introduction}

Worker's mental health concerns have been the subject of an increasing number of investigations. It is known the importance of performance, relationships and recognition in the work activity for the self-esteem, development and quality of life of the human being. With globalization and rapid technological evolution, there have been significant changes in the functional conditions, values and work production concepts, impacting practically the entire economically active population in the world. And this seems to have a direct relationship with excessive departures and licenses of activities requested in the various sectors or institutions of exercise. In this context the Burnout Syndrome (BS), occupational burnout syndrome or this process, in its different phases, deserves to be highlighted. This represents a psychosocial phenomenon associated with chronic occupational stress and consists of three dimensions: Emotional Exhaustion (EE), Depersonalization (DP) and Low or Professional Realization (LPR) [1]. Among the factors characterized as occupational stressors are reported: long working hours (overload), low qualification, lack of professional recognition and exposure to risks [2]. Interpersonal difficulties, lack of autonomy, pressure for responsibility, type of bond or nature of 
activities and work instability, as well as conflicts between the family and the family [3]. Sociodemographic and occupational factors for the development of Burnout can be linked to three different types of behavior: "frenetic" that encompasses involved and ambitious subjects, who sacrifice their activities and personal life for the jobs; "underchallenged", indifferent, bored workers, who cannot find personal development in their actions and the "worn-out", subjects where neglect is a characteristic associated with the lack of confirmation of their efforts, due to the little control or devaluation of the results from these [4]. BS can reach any professional, but it has its focus of study in activities related to teaching and health services, as they involve a dynamic relationship of intense contact with people who need assistance [5,6]. With regard to professionals directed to health care for children and adolescents, in addition to the attention to individuals in phases of active development and requiring a differentiated approach (due to the inherent characteristics of the age group), they maintain a constant interaction with the relatives or caregivers; a condition that can create situation of conflict (stress and mental fatigue), with implications on the quality of the service offered [7]. The present study was justified, according to what was previously exposed and considering the lack of needed information in this subject. This has the overall objective of determining the prevalence and risk factors for Burnout in child and adolescent health care workers.

\section{Methods}

A cross-sectional study was performed with descriptive and analytical statistics, based on a margin of error of 5.0\%. The study areaincluded the city of Campina Grande, Paraiba State, Northeastern Brazilian. The population comprised 87 municipal health professionals for children and adolescents officially recognized (doctors, dentists, nurses, psychologists and physiotherapists). The inclusion criteria: professional exercise in the area of health care for children and / or adolescents (six months at least) during data collection time. Professionals who were in a function that was not compatible with the training area emphasized or who did not voluntarily participate in the survey were excluded. In the initial phase of this research, when a pilot study was developed with professionals linked to university teaching, two adapted versions of the MBI (Maslach Burnout Inventory) Chafic Jbeili version [8], (more directed to Brazilian teachers and educators), and the MBI-HSS (Maslach Burnout Inventory for Human Services Survey), a widely used version in the health area [9]. From a high internal consistency (Cronbrach 0 0.88) and a better understanding of the first one was established for the present study. It was adopted a questionnaire as instrument for data collection: socio-demographic, training, occupation, free time activities and MBI variables considered in the analysis. There was a reduction in the number of items to 20 (MBI version), preserving the structure and the three dimensions that characterize SB: nine regarding emotional exhaustion [1-3,6,1014], [4,7-9,15-17], and seven were related to reduced professional achievement $[5,12,15,18,19]$. The frequency with which each feeling occurs in the areas from a psychometric scale, with values from 1 to 5 ( 1 = never, 2 = annually, 3 = monthly, 4 = weekly and $5=$ daily) is measured.

Subsequently, the sum of the points, in the form of scores: 0 to 20 points (no indication of Burnout); from 21 to 40 points (possibility of developing the syndrome - working on prevention recommendations); from 41 to 60 points (early phase of SB - seek professional help to relieve symptoms); from 61 to 80 points (the syndrome begins to settle - seek professional help to avoid aggravation of symptoms); from 81 to 100 points (considerable phase of the syndrome, but reversible). Data were analyzed by percentage and statistical measures: mean, median, deviation, minimum value and maximum value. In order to verify the existence of a significant difference between the categories of each independent variable, the statistical tests were used: Student's t-test or MannWhitney test in the comparison of two categories and F (ANOVA) or Kruskal -Wallis in the comparison between three categories. In the case of significant difference through the F test (ANOVA), Tukey's multiple comparisons (between pairs of categories). Tests were rejected when the normality hypothesis was rejected. To verify the hypothesis of normality of the data the Shapiro-Wilk test was used and with a view to the hypothesis of equality of variances the Levene F test was performed. The statistical program used to enter the data and obtain the statistical calculations was the SPSS (Statistical Package for the Social Sciences) in version [20]. This work respected the universal principles that govern bioethics in research and human rights. The project was analyzed and approved under CAAE 0370.0.133.000-11, by the Research Ethics Committee of the State University of Paraiba.

\section{Results}

For a universe of 87 the total sample comprised 74 (85\%), who accepted to participate in this research. Of these, 11 (14.9\%) were evaluated in the pilot study, being discarded from the final sample, due to necessary adjustments in the determined sociodemographic variables. Among the 63 professionals who participated in the final sample, the following distribution occurred according to the health specialty: 47 physicians, 5 psychologists, 5 nurses, 4 dentists and 2 physiotherapists. The subjects' ages ranged from 23 to 76 years, with a mean of 41 years $(S D=12.33)$ and a median of 40 years. According to the sociodemographic characteristics of the professionals interviewed, the highest percentage $(47.6 \%)$ corresponded to those who were between 30 and 49 years old, followed by those aged 50 years or older (28.6\%) or up to 29 years (23.8\%). Of these, the majority (90.5\%) were female. In relation to the marital status, $66.7 \%$ were married or in a stable / consensual union and $71.4 \%$ lived with a family, followed by $19 \%$ who lived with their parents and 9.5\%, who lived alone or in another situation not specified.

Children or dependents were registered to $61.9 \%$ of the professionals, being $41.3 \%$ with more than two dependents. The 
highest monthly income range (47.6\%) existed for amounts up to 10 minimum wages in force at the time of data collection, approximately U\$ 3,060. From the data on training and occupation, the two highest percentages corresponded to graduates less than 10 years ago (41.3\%) and more than 20 years (34.9\%); approximately $74.6 \%$ of the interviewees were physicians; the majority (73.0\%) had a postgraduate degree in residence or specialization, with a lower percentage of doctors (4.8\%). The public service covered most of the labor ties (50.8\%), with a higher percentage $(42.9 \%)$ of these professionals with only one reported employment relationship. Regarding the time in the service, the two most frequent bands were respectively less than one year $(38.1 \%)$ and more than 10 years (36.5\%). More than half (57.1\%) of the respondents worked three shifts and only $9.5 \%$ worked only one shift; where $66.7 \%$ of these $(2 / 3$ of the sample) reported working up to 40 hours per week and the others above the weekly workload considered. Still in the previous context, when questioned about the average daily number of patients (children or adolescents) attended daily, $46 \%$ of the individuals in the sample were higher than 50 . Turning to the existence of weekly free time dedicated to personal life, $84.1 \%$ stated to carry out leisure activity. According to the Burnout dimensions and the total score classification for the MBI; by its analysis the group of professionals presented predominantly low level of emotional exhaustion (57.1\%), moderate level of depersonalization (71.4\%), and a high level of low professional achievement (100\%).

Regarding the total classified, approximately half (50.8\%) had the possibility of developing Burnout, followed by $46.0 \%$ with this process in the initial phase; to $3.2 \%$ the syndrome was already beginning to settle. No patients were searched without evidence or at a considerable stage for this disease. The statistics of SB's dimensions a there is a non-high variability (values of standard deviations less than $35 \%$ of the respective mean values). The results of the classifications of the averages were: low for EE, moderate for ED and high RRP. The total score was classified as Burnout in the initial phase. There was a significant difference between the marital status and the income range in depersonalization: the mean was one unit (1.00) higher among married / stable union than among single / widowed / separated (7.86 x 6.86) and increased with the income range, with 6.90 in the range of up to 10 minimum wages (up to $\mathrm{U} \$ 3,060$ ), 7.82 in the range with 11 or more minimum wages (equal to or greater than $U \$ 3,500$ ) and 8.38 in the range of 21 or more minimum wages (equal to or greater than $U \$ 6,400$ ). Through the multiple comparisons tests there was a significant difference between those who had income up to 10 minimum wages with those who had income with 21 or more minimum wages. "Emotional exhaustion" and free time for leisure or physical activities was the only variable with statistical significance $(\mathrm{p}<0.05)$.

\section{Discussion}

Burnout, a process started with excessive and prolonged levels of stress in the work environment, has been considered a major occupational problem today, a challenge to global public health. This is due to a growing number of people, a lack of a better and broader approach on the subject, with undiagnosed and properly treated staff and the complexity of the repercussions involved, not only from an organizational or institutional point of view, but also in the quality of life of the employees, professionals in the areas of education, human and health. Thus, and due to the lack of information on its prevalence, epidemiological studies need to be encouraged [10-12]. There are four theoretical conceptions for the diagnosis of SB, based on possible factors related to its etiology: clinical, organizational, socio historic and sociopsychological, this is the most used in the studies. In this sense and for the evaluation of the phenomenon, the instruments still show weaknesses, particularly regarding the comprehension and viability of application in populations with differentiated characteristics. Many adaptations have been employed for the Maslach Burnout Inventory (MBI), still recognized as the gold standard for this, because of its complexity. It is reinforced that these represent a screening for Burnout, not replacing the evaluation and closure of the diagnosis, by medical professionals and psychology [13]. In the present study, with the approach directed to health care professionals for children and adolescents, the great majority of the sample was female. The predominance of women in health care has been highlighted. The "ideal profile" of these caregivers for the above mentioned target population is related to the expanded role of motherhood, which strengthens their empathic commitment to patient care, and is an advantageous aspect in relation to non-development of BS.14 On the other hand, the dual workload of women (in the exercise of work and at home, as wife and mother), still emphasized in societies, would constitute a risk factor for this phenomenon; a fact that may be associated with an implicit or explicit discrimination of women as servants and a neglect observed in male attention when in the presence of symptoms for the different phases of this problem [15]. According to the data obtained in this research, there was a greater vulnerability among the married professionals or with a stable / consensual union and in the family monthly income question, regarding the OD dimension for Burnout, there were no significant associations between the other variables investigated, in training or vocational qualification and work.

The literature consulted usually emphasizes that married or fixed partners experience feelings of greater family responsibility, with a better ability to cope with emotional problems and, consequently, a greater resistance to the development of SB, the opposite of which was verified here. It also registers an inverse and significant association between the development of BS and ages over 55 years, working time over 21 years and up to 30 years for individuals who perform activities in one shift or who have administrative positions16; associations not established in the present study, except for the lowest family income [17]. Still in the context of the dimensions of Burnout, the values achieved in the current work were low and moderate in almost all dimensions, corroborating with Bellieniet et al. [18], Cushnir and Cohen 
[19] emphasized that child care professionals tend to tolerate stressful aspects of the environment and are still motivated and engaged, with the absence of positive employment resources, such as recognition for work (including the financial component), autonomy and the use of skills, the causes most associated with high levels of Burnout dimensions (EE, DP and LRP). For Swider and Zimmerman [20], there is a greater focus of research under the organizational and labor spheres, forgetting individual-level variables such as personality, or when considering personality, focuses on a limited number of these traits. As well as individual characteristics, turnover, absenteeism and performance at work have been little discussed in the literature on burnout. The results in the present study should be analyzed considering the inherent limitations of the methodology adopted and the lack of a control group (this is particularly related to the information difficulties regarding the universe of health professionals), as well as the sample size.

\section{Conclusion}

Although the prevalence of characteristics associated with Burnout Syndrome was considerable (49.2\%) for this group, there was no positive association between the variables related to free time and work, except for the sociodemographic variables, monthly family income and marital status.

\section{References}

1. Finney C, Stergiopoulos E, Hensel J, Bonato S, Dewa CS (2013) Organizational stressors associated with job stress burnout in correctional officers: A systematic review. BMC Public Health 13: 82.

2. Bridgeman PJ, Bridgeman MB, Barone J (2018) Burnout syndrome among health care's professionals. Am J Health Syst Pharm 75(3): 142152.

3. Mattei A, Fiasca F, Mazzei M, Abbossida V, Bianchini V (2017) Burnout among health care workers at L'Aquila: its prevalence and associated factors. Psychol Health Med 22(10): 1262-1270.

4. Montero Marín J, Garcia Campayo J, Fajó Pascual M, Carrasco JM, Gascón S, et al. (2011) Sociodemographic and occupational risk factors associated with development of different burnout types: the crosssectional University of Zaragoza study. BMC Psychiatry 11: 49.

5. Vercambre MN, Brosselin P, Gilbert F, Nerrière E, Kovess Masféty V (2009) Individual and contextual covariates of burnout: a cross-sectional nationwide study of French teachers. BMC Public Health 9: 333.
6. Wood BD (2009) Turnover among healthcare professionals. Radiol Manage 31(4): 24-29, 30-31.

7. Al Mendalawi MD (2018) Assessment of pediatric residents' burnout a tertiary academic centre. Saudi Med J 39(5): 528.

8. Bispo AA (2006) Stress and work: social workers in the sights of Burnout. In. Multidimensional methodologies in human sciences. Brasília: Liber Book Publisher, p. 85-106.

9. Pisanti R, Lombardo C, Lucidi F, Violani C, Lazzari D (2013) Psychometric properties of the Maslach Burnout Inventory for Human Services among italian nurses: a test of alternative models. J Adv Nurs 69(3): 697-707.

10. Berger M, Schneller C, Maier W (2012) Arbeit, Psychische Erkrankungen und Burn-out. Der Nervenarzt 83(11): 1364-1372.

11. Geraedts AS, Kleiboer AM, Wiezer NM, van Mechelen W, Cuipers P (2013) Web-based guided self-help for employees with depressive symptoms (Happy@Work): Design of a randomized controlled trial. BMC Psychiatry 16: 61.

12. Sandmark H, Renstig M (2010) Understanding long-term sick leave in female white-collar workers with burnout and stress-related diagnoses: A qualitative study. BMC Public Health 10: 210.

13. Escribà Aguïr V, Artazcoz L, Pérez Hoyos S (2008) Efecto Del ambiente psicosocial y de la satisfacción laboral em el síndrome de burnout em médicos especialistas. Gac Sanit 22(4): 300-308.

14. Swider BW, Zimmerman RD (2010) Born to Burnout: A Meta-Analytic Path Model of Personality, Job Burnout, and Work Outcomes. J Vocat Behavior 76(3): 487-506.

15. West CP, Dyrbye LN, Satele DV, Sloan JA, Shanafelt TD (2012) Concurrent validity of single-item measures of emotional exhaustion and depersonalization in burnout assessment. J Gen Intern Med 27(11): 1445-1452.

16. Padilla M, Andre C, Gómez Restrepo C, Rodríguez V, Dávila M, etal. (2009) Prevalencia y características Del síndrome de agotamiento profesional (SAP) em docentes de três colégios públicos de Bogotá (Colombia). Rev colomb psiquiatr 38(1): 50-65.

17. Gutiérrez Bedmar M, Gómes Aracena J (2009) Valores de referencia para la exposición a lós riegos psicosociales em la poblaicón Asalariada em España. Rev Esp Salud Publica 83(3): 473-474.

18. Bellieni CV, Righetti P, Ciampa R, Iacoponi F, Coviello C, et al. (2012) Assessing burnout among neonatologists. J Matern Fetal Neonatal Med 25(10): 2130-2134.

19. Poghosyan L, Clarke SP, Finlayson M, Aiken LH (2010) Nurse burnout and quality of care: cross-national investigation in six countries. Res Nurs Health 33(4): 288-298.

20. Kataoka HU, Koide N, Hojat M, Gonnella JS (2012) Measurement and correlates of empathy among female Japanese physicians. BMC Med Educ 22: 12-48.

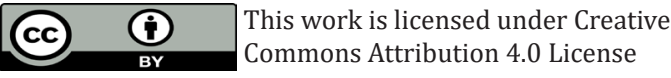

To Submit Your Article Click Here:

Submit Article

DOI: 10.32474/IPDOAJ.2019.02.000142

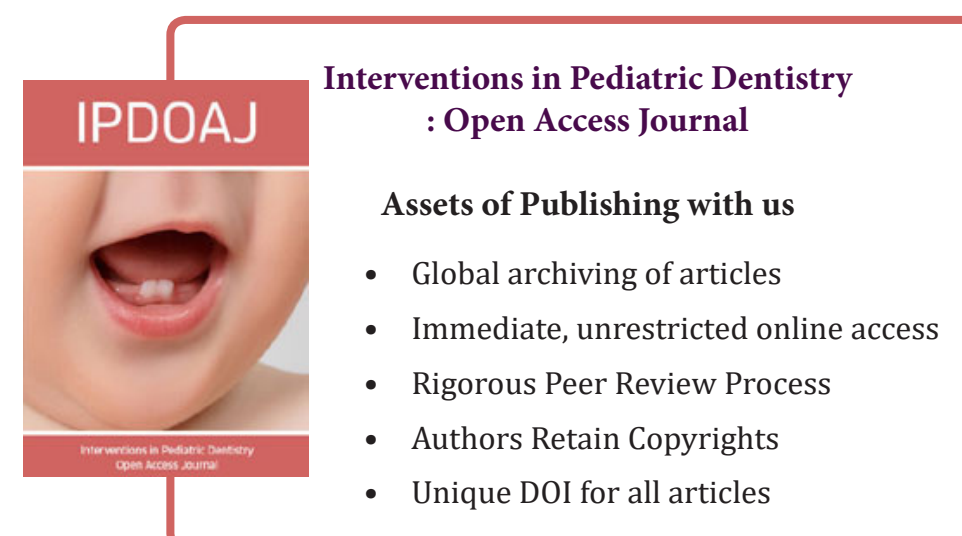

Citation: Luciana de B C F, Armiliana S do N, Alessandro L C, Criseuda M B B, Rosa M M de M S M C. Scores and Risk Factors Associated with Burnout Among Professionals of Child and Adolescent Health Care. Inter Ped Dent Open Acc J 2(4)- 2019. IPD0AJ.MS.ID.000142. DOI: 10.32474/IPDOAJ.2019.02.000142. 